\title{
Substrate-controlled divergent synthesis of enaminones and pyrroles from indolizines and nitroso compounds
}

\author{
María José González-Soria ${ }^{[a]}$ and Francisco Alonso*[a]
}

\begin{abstract}
It is imperative to learn new synthetic transformations to succeed in drug discovery and development. We report the substrate-driven synthesis of $\beta$-enaminones and $\mathrm{N}$-aryl pyrroles from indolizines and nitrosoarenes; aryl-substituted indolizines lead to $\beta$ enaminones in a regio- and diastereoselective manner, whereas alkyl-substituted indolizines produce tetrasubstituted pyrroles. All products contain a pyridine unit, the second most abundant ring (after phenyl) in the FDA Orange Book. In both cases, the reactions proceed at room temperature without any catalyst. Moreover, both types of products can be obtained in one pot from commercial materials as well as at a gram scale. It is worthy of note that the regioselectivity of the $\beta$-enaminones is inaccessible by the standard literature methods and their utility has been exemplified in the synthesis of diverse heterocycles. We have made every endeavor to put forward the corresponding reaction mechanisms based on thorough experimental work.
\end{abstract}

\section{Introduction}

Innovations in synthetic organic chemistry are crucial to advance in drug discovery. ${ }^{[1]}$ In this context, the pyridine ring is the second most recurrent ring (after phenyl) in the small-molecule drug list of the FDA Orange Book, but is also present in manifold agrochemicals. ${ }^{[2]}$ The pyrrole ring ${ }^{[3 a]}$ can be found in numerous natural products (e.g., lamellarin $\mathrm{O}, \mathrm{I})^{[3 \mathrm{~b}]}$ as well as in the aforementioned list, ${ }^{[2 a]}$ albeit it is relatively less frequent in drugs (Figure 1). Nevertheless, the best-selling pharmaceutical within the recent past, atorvastatin (II, a cholesterol-lowering agent), is comprised of a polysubstituted pyrrole ring. ${ }^{[3]}$ The latter ring is represented in other best-selling drugs, such as sunitinib (anticancer agent), ${ }^{[3]}$ or in agrochemicals, such as the fungicides fenpiclonil (III, Beret ${ }^{\circledR}$ ) and fludioxonil $\left(\right.$ Celest $\left.^{\circledR}\right) \cdot{ }^{[3 \mathrm{~d}]}$ The N-arylated pyrroles IV $^{[3 e]}$ and TDR37250 (V) ${ }^{[3]}$ have been identified as powerful substances for the treatment of leishmaniasis and malaria, respectively.

On the other hand, enaminones can be considered push-pull olefins which merge the nucleophilic character of the enamines with the electrophilic one of the enones. ${ }^{[4]}$ The enaminone moiety is part of the structure of natural products, such as the glucose-lowering (-)-multiflorin (VI), ${ }^{[5 a]}$ and of some synthetic compounds, such as the anticonvulsant VII[5b] (with comparable potency to that of diazepam) or the fluorinated quinolone antibacterials (e.g., ciprofloxacin, VIII) ${ }^{[5 c]}$ (Figure 1). In addition,

[a] Dr. María José González-Soria and Prof. Dr. Francisco Alonso Instituto de Síntesis Orgánica (ISO) and Departamento de Química Orgánica, Facultad de Ciencias

Universidad de Alicante,

Apdo. 99, 03080 Alicante, Spain

E-mail: falonso@ua.es

Supporting information for this article is given via a link at the end of the document. enaminones are highly versatile scaffolds in heterocyclic chemistry ${ }^{[4 a, d, 6]}$, particularly, in the total synthesis of alkaloids. ${ }^{[4]}$ Enaminones are generally prepared through condensation and addition reactions, by acylation of enamines or cleavage of heterocycles. ${ }^{[4 a-c]}$ Among them, the condensation of primary or secondary amines with 1,3-dicarbonyl compounds is surely the most practiced method. However, the less nucleophilic aromatic amines are more reluctant to react and azeotropic removal of water is mandatory in order to shift the equilibrium towards the enaminone. Some alternative procedures mostly based on transition-metal catalysis have emerged in the last years, ${ }^{[7]}$ with those involving the transmutation of heterocycles into enaminones being uncommon. ${ }^{7 \mathrm{cc}]}$

As regards pyrroles, multitude of efficient approaches to their synthesis have been devised, ${ }^{[8]}$ mostly relying on transitionmetal catalysis ${ }^{[8 a, b]}$ and multicomponent reactions. ${ }^{[8 c, 9]} \mathrm{Pd}, \mathrm{Rh}$, $\mathrm{Au}, \mathrm{Ru}$ and $\mathrm{Cu}$ catalysts have been the most applied transition metals for this purpose, not only in MCRs but in intramolecular cyclizations ${ }^{[10]}$ or intermolecular annulations involving alkynes ${ }^{[11]}$ or other substrates; ${ }^{[12]}$ organocatalyzed procedures are also known. ${ }^{[13]}$ As in the case of the enaminones, the transformation of other heterocycles into pyrroles is barely documented. ${ }^{[14]}$ Due to the type of starting chemicals normally deployed for pyrrole synthesis, the majority of the products end with a carboxylate/carbonyl group attached to the ring. We must also underline that the $\mathrm{N}$-arylation of five-membered nitrogencontaining amino heterocycles is known to be troublesome. ${ }^{[1 a]}$

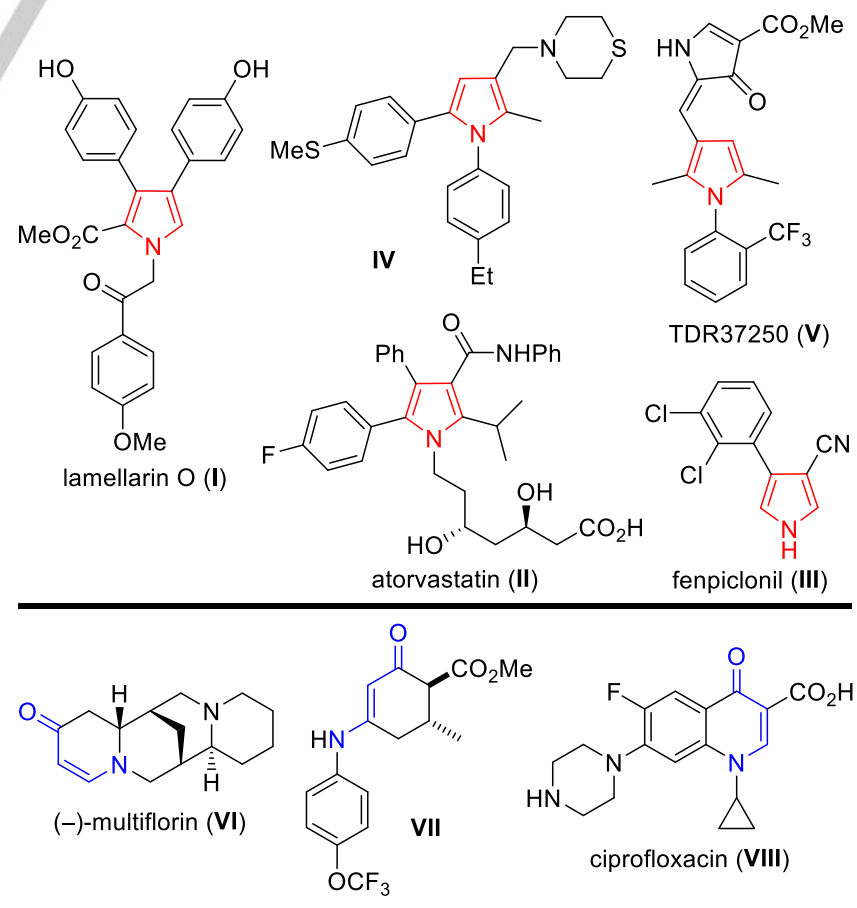

Figure 1. Biologically active pyrroles and enaminones 
In view on these antecedents, there is a certain upsurge of interest in designing novel synthetic strategies that impart functionalization and substitution patterns to enaminones and pyrroles unreachable by other routes. By virtue of our current interest in the application of copper nanoparticles ${ }^{[15]}$ to multicomponent reactions, ${ }^{[15 a]}$ we published the solventcontrolled three-component synthesis of amino-substituted indolizines and the synthesis of heterocyclic chalcones from pyridine-2-carbaldehyde derivatives, secondary amines and terminal alkynes catalyzed by copper nanoparticles on activated carbon (CuNPs/C) (Scheme 1). ${ }^{[16]}$ The reactivity of the aforementioned indolizines has been explored only recently: their heterogeneous catalytic hydrogenation led to indolizidines in a chemo- and diastereoselective manner, ${ }^{[17 a]}$ whereas an acid-base treatment furnished a new family of solvatochromic dyes through a metal-free $\mathrm{C}-\mathrm{H}$ site-selective alkenylation. ${ }^{[17 b]}$

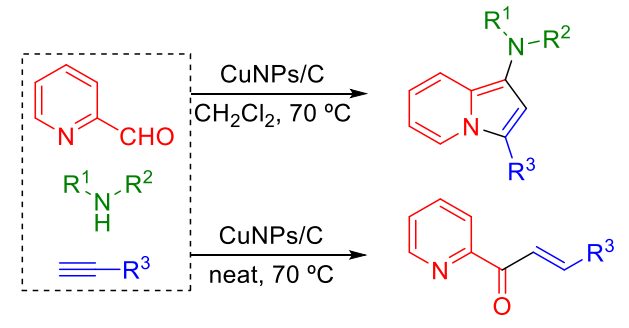

this indolizine derivative, concluding that acetonitrile was the best choice (Table 1, entry 7). The absence of solvent or presence of CuNPs/C (utilized for the synthesis of the indolzines) were detrimental to the conversion (Table 1, entries 6 and 13 , respectively).

Table 1. Optimization of the enaminone synthesis. ${ }^{[a]}$

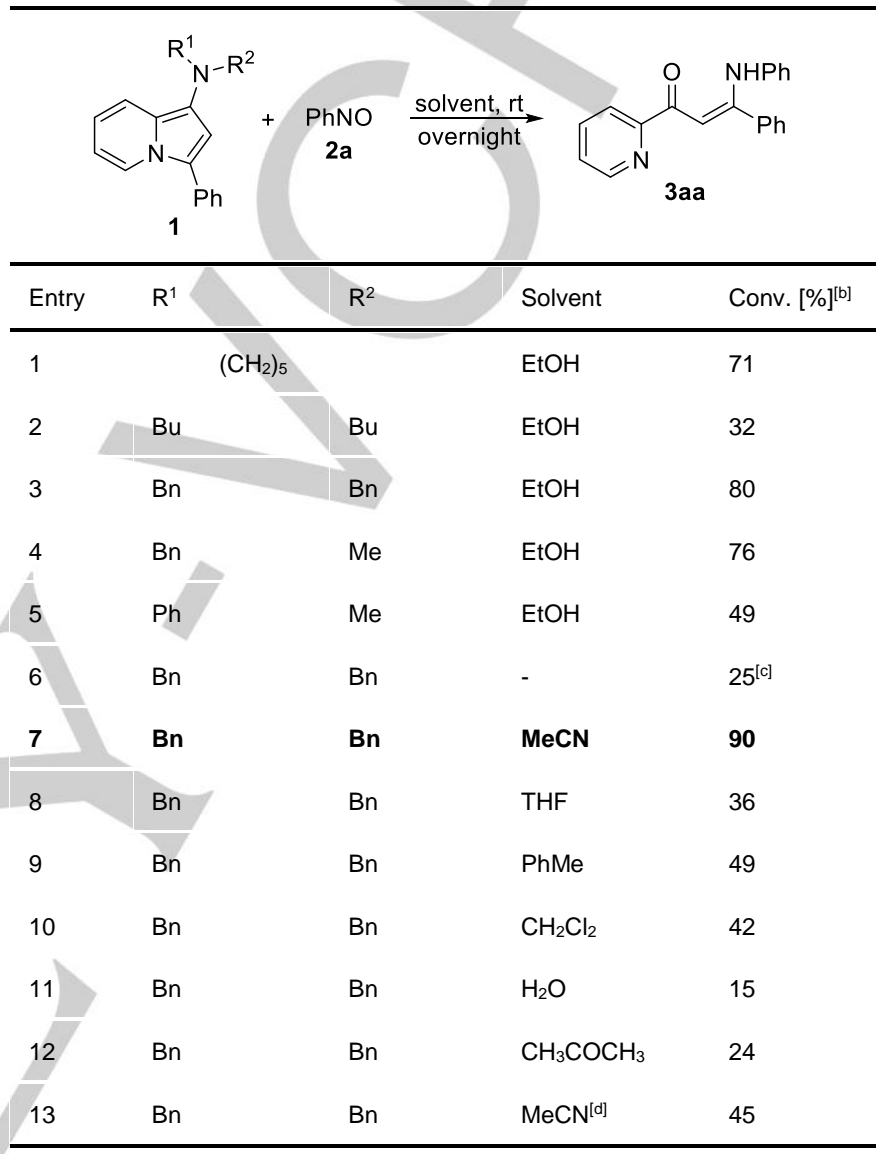

[a] Reaction conditions: 1 (0.1 mmol), 2a $(0.1 \mathrm{mmol})$, solvent $(1 \mathrm{~mL})$, rt, overnight. [b] Conversion into 3aa determined by GLC. [c] Reaction at $50{ }^{\circ} \mathrm{C}$ [d] In the presence of CuNPs/C (5 mol\%).

With the optimized conditions in hand (Table 1, entry 7), we tried to expand the procedure to other substrates (Table 2). Nitrosobenzene (2a) was combined with indolizines bearing all sort of substituents on the aryl ring at the 3-position $\left(R^{1}\right)$, i.e., electron-neutral, electron-donating and electron-withdrawing ones; the corresponding $\beta$-enaminones 3aa-3ea were formed in moderate-to-good isolated yields. The outcome for indolizines with additional substitution was uneven. For instance, the 5 methyl-substituted indolizine 1f performed much better that the (methylsulfonyl)phenyl counterpart (19), which was more reluctant to react and required warming at $50{ }^{\circ} \mathrm{C}$ for improving the yield. The product 3 ga was formed as a mixture of regioisomers (ca. 1.5:1, NMR); fortunately, the major one could be isolated by column chromatography. Similar behavior was observed for $N, N$-dibenzyl-3,5-diphenylindolizin-1-amine, which gave the final product in very low conversion as a 2:1 regioisomeric ratio (not isolated). The procedure was also 
Table 2. Synthesis of enaminones $3^{[a]}$<smiles>[R1]/C(=C/C(=O)c1cccc([R])n1)N[Ga]</smiles><smiles>O=C(/C=C(\Nc1ccccc1)c1ccccn1)c1ccccc1</smiles>

3aa $(83 \%)$<smiles>CC(=O)c1ccc(/C(=C/C(=O)c2ccccn2)Nc2ccccc2)cc1</smiles>
3ea $(76 \%)$<smiles>Cc1ccc(N/C(=C\C(=O)c2ccccn2)c2ccccc2)cc1</smiles>

$3 a b(56 \%)$<smiles>Cc1ccccc1N/C(=C\C(=O)c1ccccn1)c1ccccc1</smiles>

3af $(62 \%)$<smiles>Cc1ccc(/C(=C/C(=O)c2ccccn2)Nc2ccccc2)cc1</smiles>

3ba $(88 \%)$<smiles>Cc1cccc(C(=O)C=C(c2ccccc2)c2ccccc2)n1</smiles>

3 fa $(70 \%)$<smiles>COc1ccc(/C(=C/C(=O)c2ccccn2)Nc2ccccc2)cc1</smiles>

3 da $(65 \%)$<smiles>CCCCCC(C)(C)[Mg]</smiles>

3 ga $(35 \%)^{[b]}$<smiles>CC(=O)c1ccc(N/C(=C\C(=O)c2ccccn2)c2ccccc2)cc1</smiles>

3ac $(63 \%)$

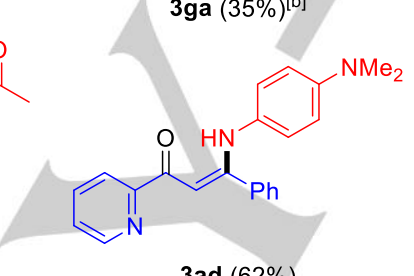

3ad $(62 \%)$<smiles>O=C(/C=C(\Nc1ccc(Br)cc1)c1ccccc1)c1ccccn1</smiles>

3ae $(68 \%)$<smiles>N#Cc1ccccc1N/C(=C/C(=O)c1ccccn1)c1ccccc1</smiles><smiles>COC(=O)/C=C(/Nc1ccccc1Br)c1ccccn1</smiles>

3ah $(74 \%)$<smiles>CCCC/C(=C/C(=O)c1ccccn1)Nc1ccc(N(C)C)cc1</smiles>

3id $(60 \%)$

[a] Reaction conditions: $1(0.3 \mathrm{mmol}), \mathbf{2}(0.3 \mathrm{mmol}), \mathrm{MeCN}(1 \mathrm{~mL})$, rt, overnight; isolated yield in parentheses. [b] Reaction at $50 \stackrel{\circ}{\circ}$; $3 \mathbf{g a}$ was obtained as a ca. 1.5:1 mixture of regioisomers.

successfully applied to the more complex indolizine $\mathbf{1 h}$, furnishing the expected product 3ha with a double pyridinyl chalcone motif. Nitrosoarenes other than nitrosobenzene were also tested (2b-2h); para-substituted representative examples with electron-donating, electron-withdrawing and halogen groups gave rise the enaminones $\mathbf{3 a b}-\mathbf{3 a e}$ in moderate isolated yields. Ortho-substituted nitrosobenzenes behaved likewise (2f-2h), though some by-product formation was observed in the case of the cyano derivative $3 \mathrm{ag}$. As an exception, a $\beta$-alkyl- $\beta$ enaminone could be also synthesized (3id), albeit only with the presence of the strong electron-releasing dimethylaminophenyl group.

The kinetic profile corresponding to the reaction of the indolizine 1a with nitrosobenzene (2a) displays the highest conversion variation in the interval 4-8 $\mathrm{h}$ (Figure 2); the progress of the reaction is much slower at the outset of the reaction and after 8 h. We also attempted to reach the enaminone in one pot from the commercial starting materials pyridine-2-carbaldehyde,

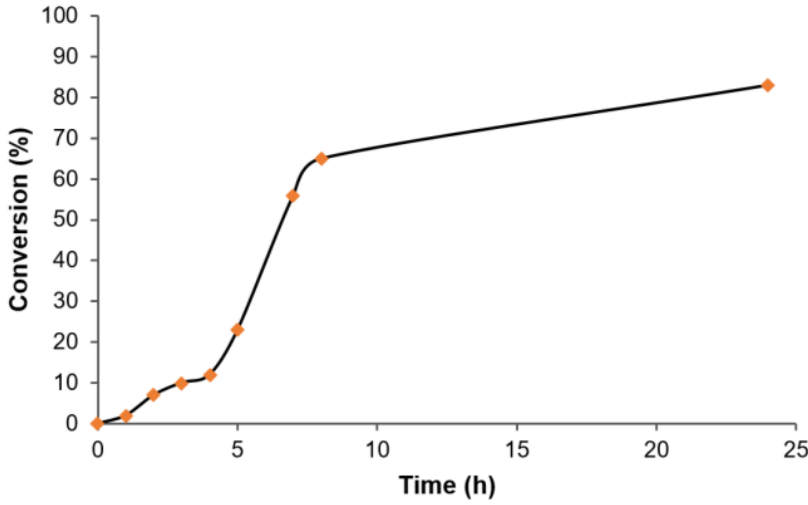

Figure 2. Plot displaying the evolution of the synthesis of the enaminone 3aa from the indolizine $\mathbf{1 a}$ and nitrosobenzene $(\mathbf{2} \mathbf{a})$. 
dibenzylamine and phenylacetylene, without the need to isolate the intermediate indolizine (Scheme 3); the moderate success of this approach might be due, in part, to the interference of CuNPs/C in the second step of the sequence (see, Table 1, entry 13). It was, however, gratifying to demonstrate that the enaminone 3aa could be synthesized with equal efficiency at a gram scale (Scheme 4). Moreover, the lack of atom economy associated with the release of dibenzylamine could be overcome by subjecting the reaction crude to acid-base work-up $(2 \mathrm{M} \mathrm{HCl}$ and $2 \mathrm{M} \mathrm{NaHCO}_{3}$, respectively); in this way, $80 \%$ of the original dibenzylamine could be recovered, what substantially decreased the $\mathrm{E}$ factor of the process.<smiles>O=Cc1ccccn1</smiles>

$$
\begin{aligned}
& +\quad \text { i) } 0.5 \mathrm{~mol} \% \mathrm{CuNPs} / \mathrm{C} \\
& \mathrm{Bn}_{\mathrm{N}^{-}} \stackrel{\mathrm{Bn}}{\stackrel{\mathrm{CH}_{2} \mathrm{Cl}_{2}, 70^{\circ} \mathrm{C}, 10 \mathrm{~h} \text {, then }}{\longrightarrow}} \\
& \begin{array}{l}
\mathrm{H} \\
+\quad \text { ii) } \\
+
\end{array} \\
& \mathrm{Ph}=
\end{aligned}
$$

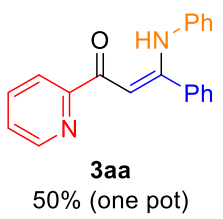
$77 \%$ (two steps)

Scheme 3. One-pot synthesis of the enaminone 3aa

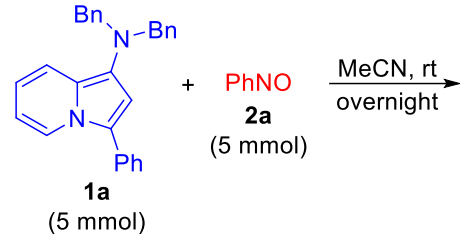

Scheme 4. Gram-scale synthesis of the enaminone 3aa. behavior could be explained in terms of copper complexation with the pyridinylcarbonyl unit of $\mathbf{8}^{[20]}$ In contrast, good conversion was attained with $\mathrm{Yb}(\mathrm{OTf})_{3}{ }^{[19 \mathrm{a}]}$ albeit towards the opposite regioisomer 3aa' (Table 3 , entry 2 ). The reaction was unproductive in the absence of catalyst (Table 3, entries 3 and $4)^{[19 b]}$ or with $\mathrm{Bi}\left(\mathrm{CF}_{3} \mathrm{CO}_{2}\right)_{3}$ (Table 3, entry 5$)$, ${ }^{[19 \mathrm{c}]}$ whereas montmorillonite $\mathrm{K}-10$ under ultrasounds ${ }^{[19 \mathrm{~d}]}$ also formed the product 3aa' in moderate conversion (Table 3 , entry 6 ). It is clear that the condensation route is not valid for the target enaminone 3aa: the picolinoyl carbonyl group undergoes preferentially the nucleophilic attack of aniline because of the larger electrophilicity of the former compared to that of the benzoyl carbonyl and, hence, this fact reinforces the utility of our strategy.

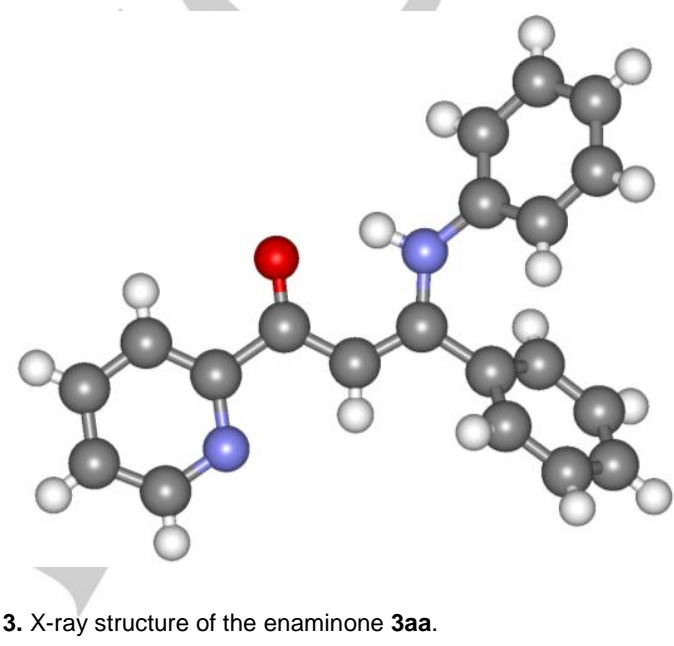

Figure 3. X-ray structure of the enaminone 3aa.

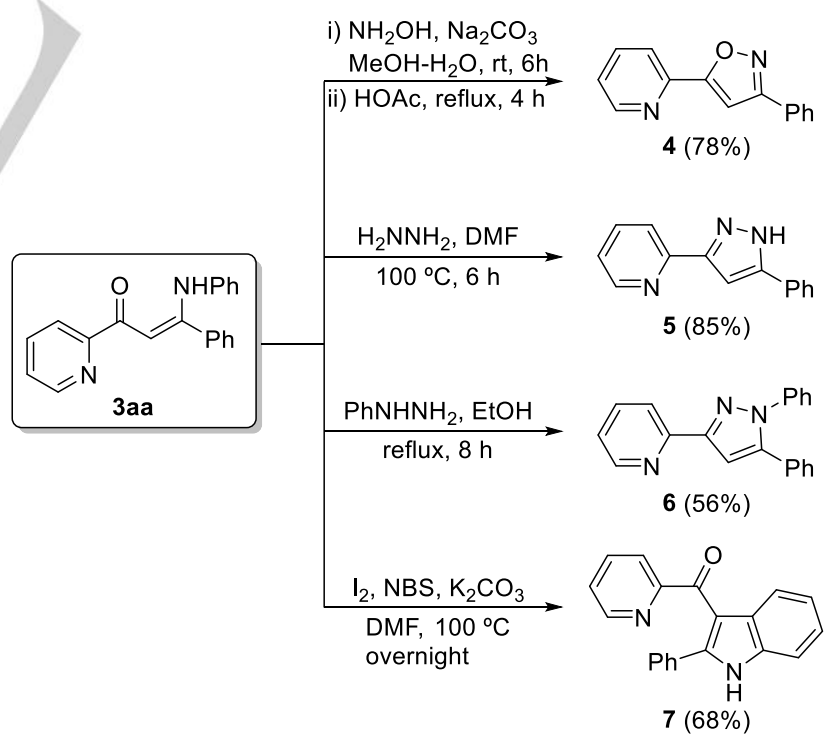

Scheme 5. Transformation of the enaminone 3aa into different heterocyclic compounds.

Synthesis of pyrroles. Indolizine $\mathbf{1 i}$ and nitrosobenzene (2a) were used as the model substrates to optimize the reaction conditions in the pyrrole synthesis (Table 4). Practically, every 
Table 3. Reaction of the 1,3-dione 8 with aniline under different conditions. ${ }^{[a]}$

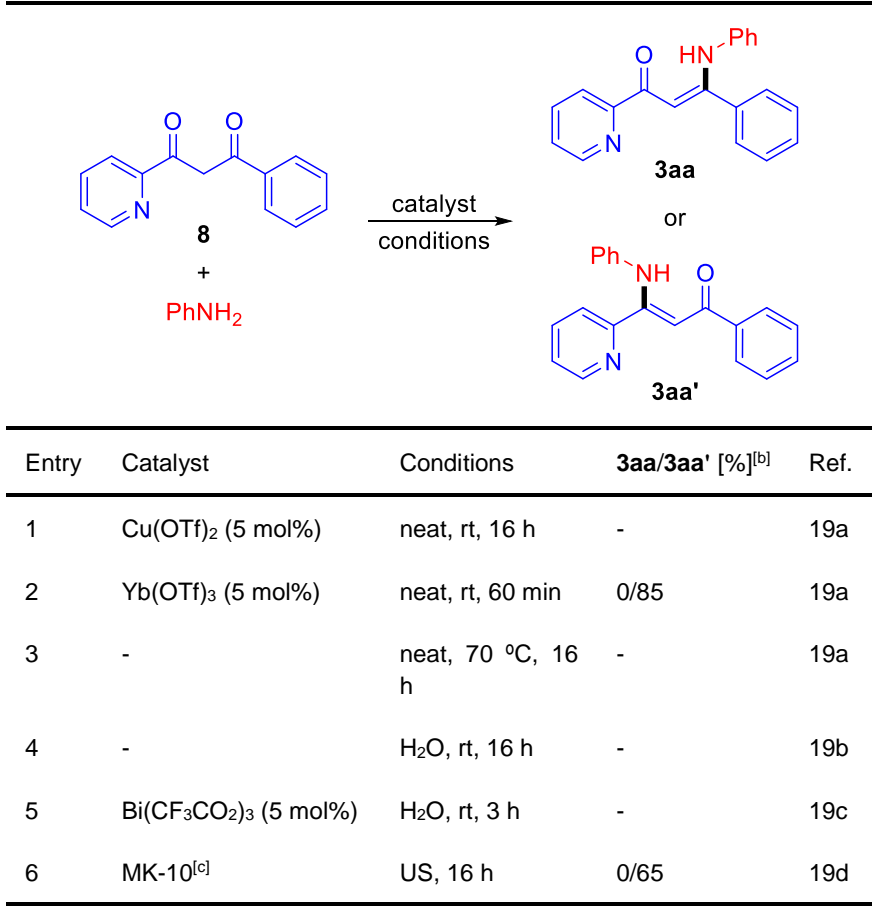

[a] 1,3-Dione $8(0.2 \mathrm{mmol})$, aniline $(0.4 \mathrm{mmol})$. [b] Conversion into 3aa and 3aa' determined by GLC. [c] Montmorillonite K-10 (60 mg).

organic solvent tested was adequate to accomplish this transformation, providing conversions above $85 \%$ for 9ia (Table 4 , entries 2-7). On the contrary, the absence of solvent or presence of water had an adverse effect, decreasing the conversion or impeding the reaction, respectively (Table 4 , entries 1 and 8). Ethanol was considered the solvent of choice because of being a recommended solvent ${ }^{[21]}$ and achieving the highest conversion (Table 4, entry 2). To our delight, the reaction proceeded under ambient conditions and, as occurred in the case of the $\beta$-enaminones, the presence of CuNPs/C exerted a negative effect on the conversion (Table 4, entry 9 ). These mild and green conditions were extended to an array of indolizines and nitroso compounds (Table 5). First, the amino group at the 1-position of the indolizine was varied: the expected pyrroles were produced in good-to-excellent isolated yields for dibenzyl, dialkyl, cyclic, alkylaryl, alkylbenzyl and chiral amino groups (9ia-9na). Pyrroles with a substituted pyridinyl, different alkyl chain length or functionalized alkyl chain were also accessible by this way but with relatively lower yields (9oa-9sa), in the latter case because of some by-product formation. Finally, the $\mathrm{N}$-aryl substituent could be modified by the choice of the nitrosoarene, recording moderate-to-good yields for the $\mathrm{N}$ arylated pyrroles 9ib-9if. It is worthwhile mentioning that product 9if is an axially chiral pyrrole, with the free rotation through the $\mathrm{C}-\mathrm{N}$ bond at room temperature being suppressed by the ortho-tolyl substituent. Axially chiral arylpyrroles can be found in bioactive natural products as well as in chiral ligands and catalysts. ${ }^{[22]}$

The reaction profile for the pyrrole synthesis notably differed from that of the enaminone synthesis: a high conversion (80\%)
Table 4. Optimization of the pyrrole synthesis. ${ }^{[a]}$

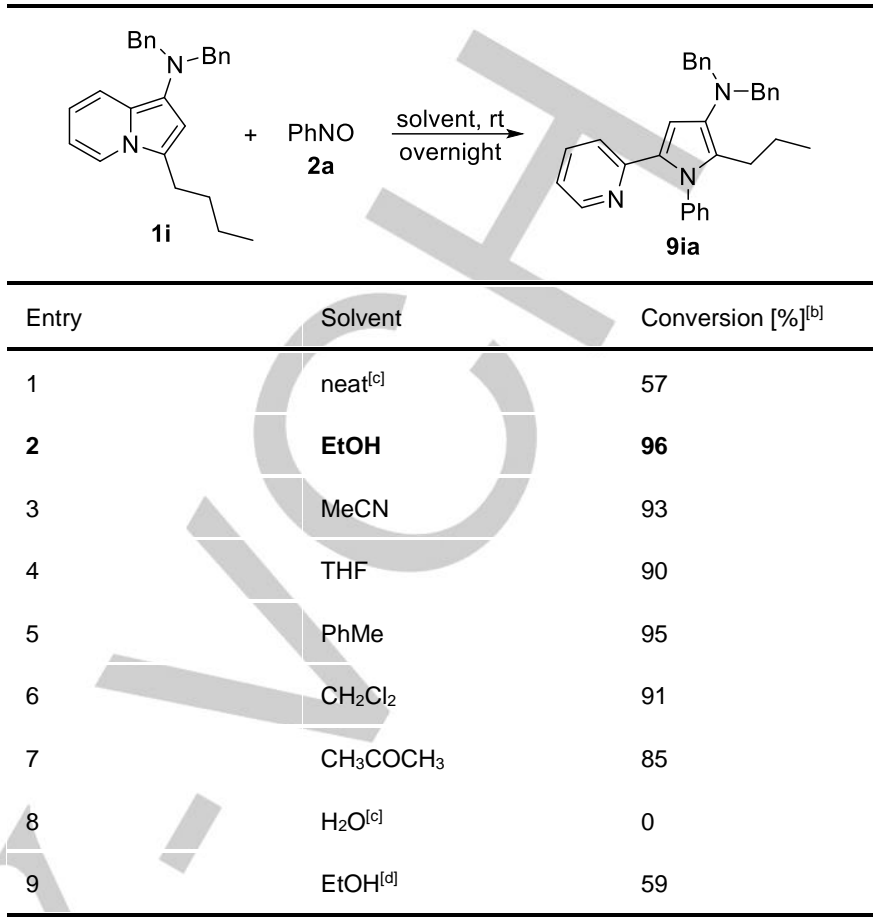

[a] Reaction conditions: $\mathbf{1 i}(0.1 \mathrm{mmol}), \mathbf{2 a}(0.1 \mathrm{mmol})$, solvent $(1.0 \mathrm{~mL}), \mathrm{rt}$, overnight. [b] Conversion determined by GLC. [c] Reaction at $50{ }^{\circ} \mathrm{C}$. [d] In the presence of CuNPs/C (5 mol\%).

was reached after only $1 \mathrm{~h}$ at room temperature, continuing to completeness after $6 \mathrm{~h}$ (Figure 4). An effective one-pot synthesis of pyrrole 9ia from commercial substances was shown to be plausible following a multicomponent synthesis of the indolizine and nitroso compound addition sequence (Scheme 6). Cul is recommended as catalyst instead of CuNPs/C in order to improve the yield of the intermediate 3-alkylindolizine. Furthermore, the simplicity of the experimental operation and satisfactory reproducibility allowed the gram-scale synthesis of the indole 9ia (Scheme 7). The structure of the pyrroles 9 was confirmed by X-ray crystallographic examination of the derivative 9ia (Figure 5). ${ }^{[18]}$ The perpendicular arrangement of the $N$ phenyl group with respect to the pyrrole ring accounts for the symmetry break when introducing an ortho-methyl group on that phenyl and the consequent manifestation of atropoisomerism.

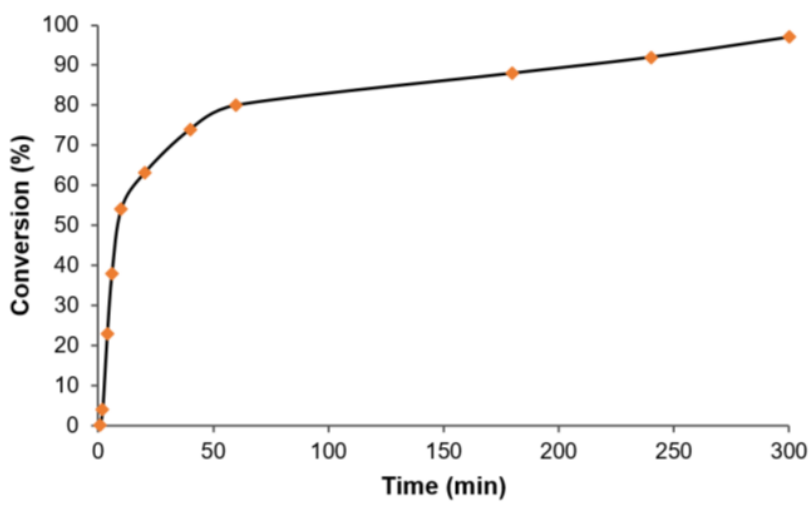

Figure 4. Plot displaying the evolution of the synthesis of the pyrrole 9ia from the indolizine $\mathbf{1 a}$ and nitrosobenzene $(\mathbf{2 a})$. 
Table 5. Synthesis of the pyrroles 9 . $^{\text {[a] }}$

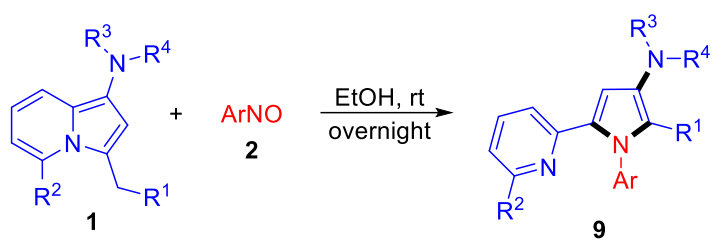<smiles>CCCc1c(N(CCC)CCC)cc(-c2ccccn2)n1-c1ccccc1</smiles>

9ia (96\%)<smiles>CCCc1c(N(Cc2ccccc2)[C@@H](C)c2ccccc2)cc(-c2ccccn2)n1-c1ccccc1</smiles>

9na (43\%)<smiles>CCCCN(CC(C)C)c1cc(-c2ccccn2)n(-c2ccccc2)c1CCC#N</smiles>

9sa (36\%)<smiles>CCCCc1cc(-c2ccccn2)n(-c2ccccc2)c1CCC</smiles>

9ja (74\%)<smiles>CCCc1c(N2CCCCC2)cc(-c2ccccn2)n1-c1ccccc1</smiles>

9ka $(65 \%)$

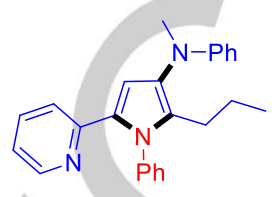

9la (80\%)<smiles>CCCc1c(N(C)Cc2ccccc2)cc(-c2ccccn2)n1-c1ccccc1</smiles>

9ma $(71 \%)$<smiles>CCCc1c(N(CCC)CC(C)C)cc(-c2cccc(C)n2)n1-c1ccccc1</smiles>

9oa (33\%)<smiles>CCc1c(C(=O)c2ccccc2)cc(-c2ccccn2)n1-c1ccccc1</smiles>

9pa (60\%)

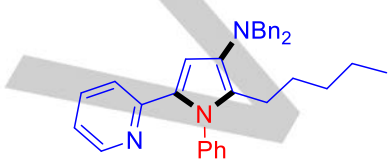

9qa (44\%)<smiles>CCCCc1c(N(CCC)CC(C)C)cc(-c2ccccn2)n1-c1ccccc1</smiles>

9ra $(40 \%)$

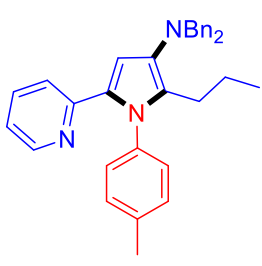

9ib $(56 \%)$

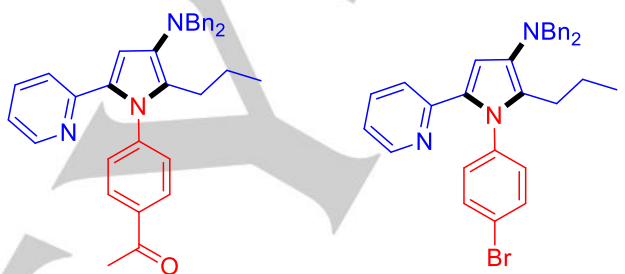

9ie $(61 \%)$<smiles>CCCc1c(N(CC)CC(C)C)cc(-c2ccccn2)n1-c1ccccc1C</smiles>

9if $(68 \%)$

[a] Reaction conditions: 1 (0.3 mmol), ArNO $(0.3 \mathrm{mmol}), \mathrm{EtOH}(1.0 \mathrm{~mL})$, rt, overnight; isolated yield in parentheses.

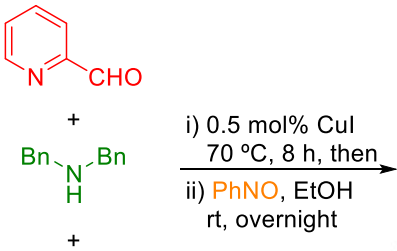

$\mathrm{Bu}=$

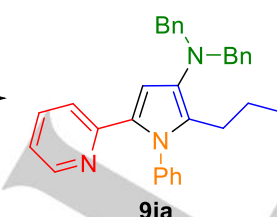

$66 \%$ (one pot) $67 \%$ (two steps)

Scheme 6. One-pot synthesis of the pyrrole 9ia.

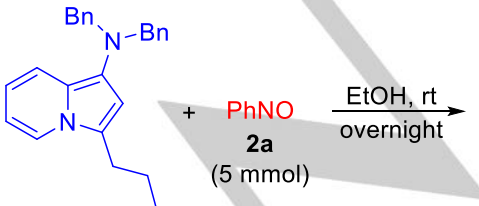

$1 \mathrm{i}$

(5 mmol)

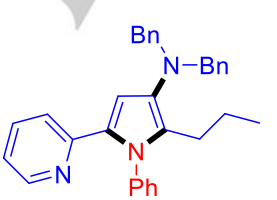

9ia

$76 \%$

$(1.74 \mathrm{~g})$

Aliphatic nitroso compounds were found to be difficult to prepare in pure form and rather unreactive under the standard reaction conditions for the synthesis of $\beta$-enaminones and pyrroles.

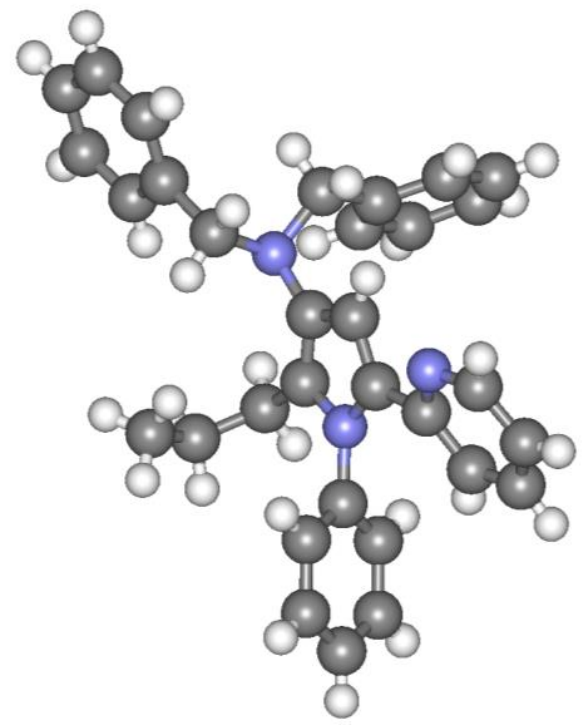

Scheme 7. Gram-scale synthesis of the pyrrole 9ia

Figure 5. X-ray structure the pyrrole 9ia 


\section{Reaction mechanisms}

Different studies were carried out in order to get an insight into the reaction mechanism for the formation of the two products, the $\beta$-enaminones and the pyrroles.

\section{Synthesis of $\beta$-enaminones}

First, a series of labelling experiments was carried out. The starting indolizine 1a-[D] was synthesized from pyridine-2carbaldehyde, deuterated dibenzylamine and deuterated terminal alkyne. Then, it was subjected to the standard conditions showing a total loss of $D$ in the $\beta$-enaminone 3aa (Scheme 8a, Figures S3 and S4). Another experiment consisted in the synthesis of $3 \mathbf{a a}$ in a mixture of deuterated solvents, $\mathrm{CD}_{3} \mathrm{CN}-\mathrm{D}_{2} \mathrm{O}(1: 0.4)$, observing the incorporation of $\mathrm{D}$ into the final product (by ${ }^{1} \mathrm{H}$ NMR of the reaction crude) but mainly at the nitrogen atom of the amine ( $98 \% \mathrm{D}$, Scheme $8 \mathrm{~b}$, Figure S5). The last experiment was carried out under the standard conditions, but adding a small amount of labeled water $\left(\mathrm{H}_{2}{ }^{18} \mathrm{O}\right.$, Scheme $8 \mathrm{c}$, Figure S6); the incorporation of ${ }^{18} \mathrm{O}$ into the final structure was virtually zero. These results suggest that the $2-\mathrm{H}$ in $\mathbf{1 a}$ is exchangeable for water protons (e.g., air or solvent humidity) and that the $O$ of the $\beta$-enaminone could come from the nitroso compound.

$$
\text { (a-[D] }
$$<smiles>CCCCNc1cc2ccccn2c1-c1ccccc1</smiles>
$\stackrel{\mathrm{PhNO}(2 \mathrm{a})}{\mathrm{CD}_{3} \mathrm{CN}-\mathrm{D}_{2} \mathrm{O}}$ rt, overnight 1a

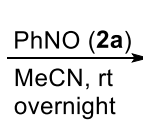<smiles>O=C(/C=C(\Nc1ccccc1)c1ccccn1)c1ccccc1</smiles>
$82 \%$ yield $0 \% \mathrm{D}$<smiles>[2H]N(/C(=C\C(=O)c1ccccc1)c1ccccn1)c1ccccc1</smiles>

(b) 3 aa- $[\mathrm{D}]$
$67 \%$ yield $98 \% \mathrm{D}$

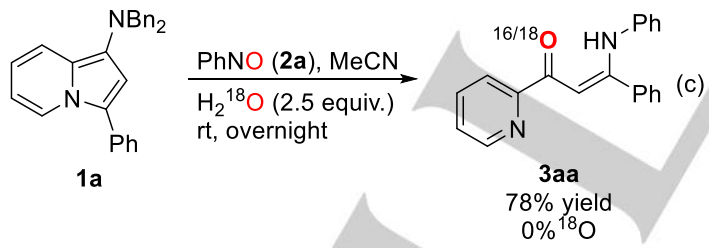

Scheme 8. Labeling experiments in the synthesis of 3aa.

The radical traps 2,2,6,6-tetramethylpiperidine-1-oxyl (TEMPO) and 2,6-di-tert-butylphenol (2,6-DTBP), 1 equiv. each, were added under the standard conditions in order to prove any participation of radicals in the reaction mechanism; they did not alter the outcome of the processes as the final product was obtained in good conversions and the radical traps were recovered unchanged (Scheme 9). Those results are in concordance with an ionic reaction pathway.

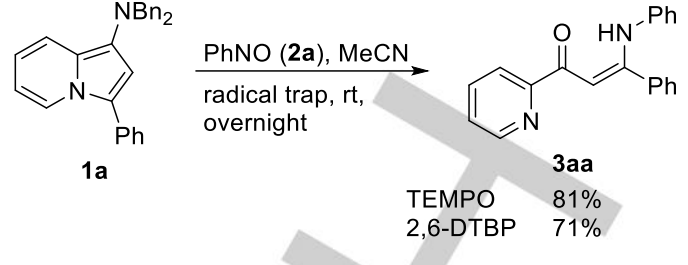

Scheme 9. Synthesis of 3aa in the presence of radical traps.

The effect of the atmosphere was found to be highly revealing in the synthesis of $\beta$-enaminones (Figure 6). Neither the use of molecular oxygen nor an inert atmosphere (using dry MeCN) were beneficial for the reaction rate. Conversely, the reaction was accelerated by air in MeCN or in the presence of water, being almost complete after $2 \mathrm{~h}$ in the latter case. It can be deduced that the air humidity and water act as proton sources favoring the process, whereas the lower rate attained with $\mathrm{O}_{2}$ seems to support the fact that it has not structural contribution to the product.

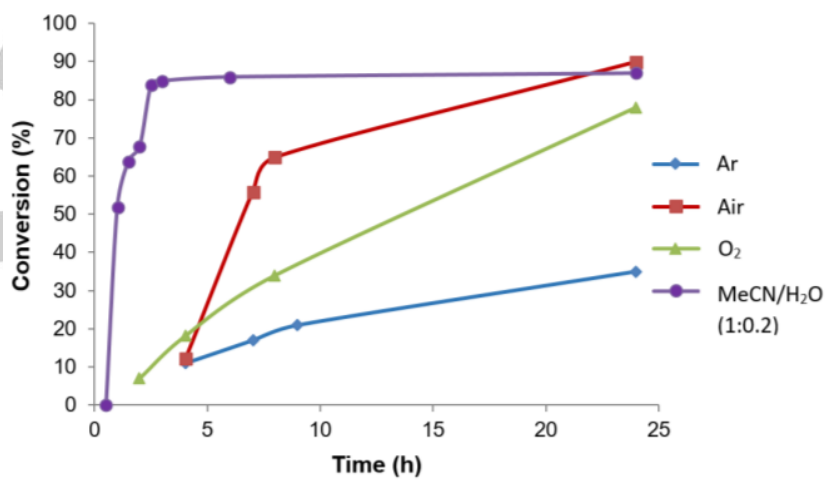

Figure 6. Reaction profiles for the synthesis of 3aa under different atmospheres.

It is known that the $\mathrm{C} 1$ and $\mathrm{C} 3$ of the indolizine nucleus are activated toward electrophiles in terms of resonance stability. ${ }^{[23]}$ We believe that indolizines bearing an aromatic 3-substituent could preferentially react with ArNO through the $\mathrm{C} 3$, due to better charge stabilization and, maybe, $\pi-\pi$ interactions, whereas the reaction might take place through $\mathrm{C} 1$ in the case of 3-alkyl substituted indolizines (Scheme 10).
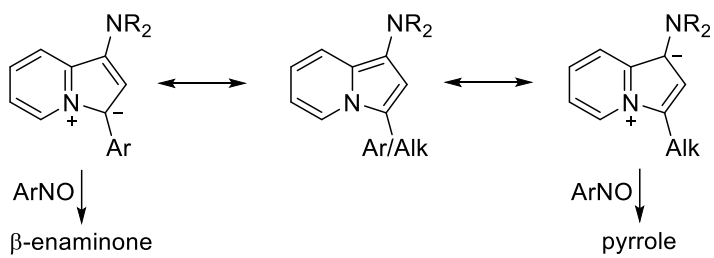

Scheme 10. Resonance structures for indolizines 1. 
With all these results in hand, the following reaction mechanism (exemplified for indolizine 1a) was envisaged for the formation of the $\beta$-enaminones 3 (Scheme 11). First, nitrosobenzene could act as an electrophile to form a $\mathrm{C}-\mathrm{N}$ bond at the 3 position. Ring opening involving the resonance of the dibenzylamino group followed by intramolecular 5-exo-dig cyclization would furnish a dihydroisoxazole intermediate. Alternatively, the latter intermediate could be obtained via a [3+2] cycloaddition reaction. Dibenzylamine elimination followed by isoxazole ring opening would provide the corresponding $\beta$-enaminone. The redox step necessary for the $\mathrm{N}-\mathrm{O}$ bond cleavage is the most intriguing step in the postulated mechanism. The likelihood of dibenzylamine acting as reducing agent should not be totally disregarded, although despite being a readily oxidizable amine, ${ }^{[24]}$ the corresponding imine has been detected as a minor byproduct. Another proposal consists in dibenzylamine or water promoting the $\mathrm{N}-\mathrm{O}$ bond cleavage. The fact that water accelerates the reaction could be related to water acting as a proton source (as two new $\mathrm{N}-\mathrm{H}$ bonds are formed) and cleaving the $\mathrm{N}-\mathrm{O}$ bond. Taking into account that nitrosoarenes may exist as dimeric species, an analogous alternative reaction mechanism has been proposed involving these dimers (Scheme S1). The 2-D/H exchange observed (Scheme 8a) could be explained through protonation-deprotonation processes of some of the intermediates and enamine-imine or enol-keto tautomerism. retained in the product 9ia under the standard conditions (Scheme 12a, Figures S7 and S8), and a marginal deuterium incorporation was noted when the reaction of $1 \mathbf{i}$ was conducted in $\mathrm{CD}_{3} \mathrm{CD}_{2} \mathrm{OD}$ (Scheme 12b). As happened in the case of the enaminones, the reaction was faster in air than in oxygen, though the presence of water did not have the pronounced positive effect observed for the former (Figure 7, Figure S9).

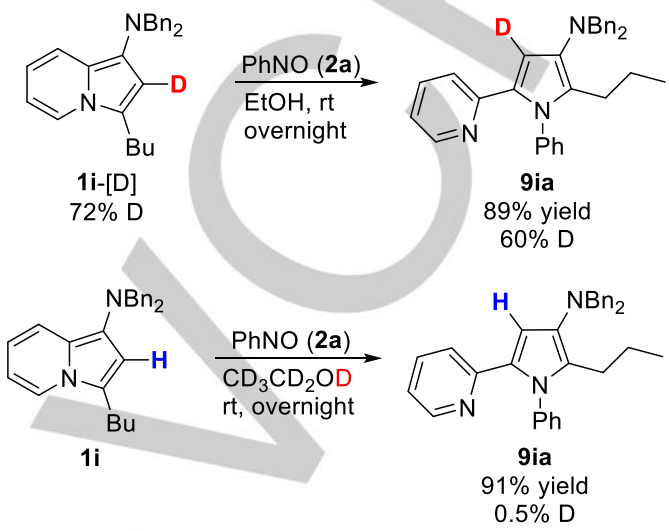

Scheme 12. Labeling experiments in the synthesis of 9ia

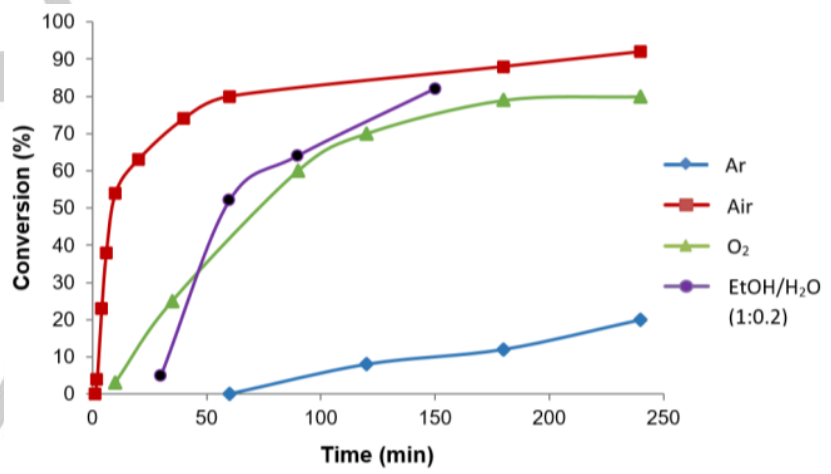

Figure 7. Reaction profiles for the synthesis of 9ia under different atmospheres.

Comparing the structure of the starting indolizine with that of the final pyrrole, it is obvious that the dibenzylamino substituent has experienced migration. Apparently, this substituent is lost during the reaction and reincorporated again into the final structure. Indeed, when the reaction was carried out in the presence of 3 equiv. of an external secondary amine, such as $\mathrm{N}$-methylaniline,

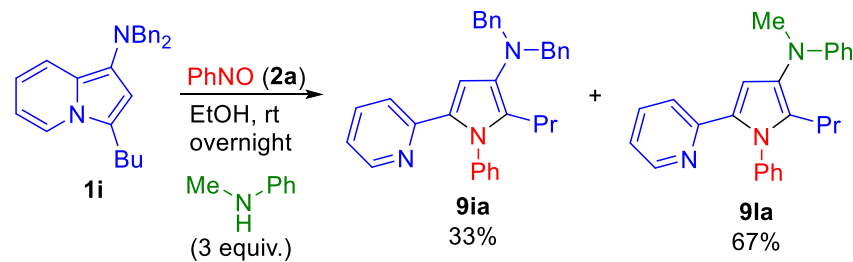

Scheme 13. Effect of the addition of an external secondary amine in the synthesis of the pyrroles.
A similar deuterium labeling strategy to that utilized for the enaminones was implemented for pyrroles though with different results. For instance, most of the deuterium content in 1i-[D] was 
the corresponding amino substituent was integrated into the pyrrole as also occurred with the dibenzylamino group, thus corroborating what hypothesized above (Scheme 13).

Several reactions were also performed to explore the feasibility of the $\beta$-enaminone being the intermediate in the formation of the pyrroles 9 (Scheme S2). The reaction of the unique $\beta$-alkyl$\beta$-enaminone we obtained (3id) with dibenzylamine did not produce the expected pyrrole (Scheme $\mathrm{S} 2 \mathrm{a}$ ); this was somewhat expected as the precursor indolizine of 3 id did not furnish the corresponding pyrrole at all. The $\beta$-enaminones 11 and 12 were also synthesized as potential intermediates in the route to pyrrole 9ia. However, under the standard conditions, neither $\mathbf{1 1}$ with dibenzylamine nor $\mathbf{1 2}$ with nitrosobenzene led to the pyrrole 9ia (Schemes S2b and S2c).

A retrosynthetic analysis of pyrrole 9ia gives two potential precursors with their tautomeric forms (Scheme 14). In-situ NMR analysis during the first hour of reaction of the indolizine $1 \mathbf{i}$ with nitrosobenzene (2a), at room temperature in $\mathrm{CD}_{3} \mathrm{CN}$, disclosed the presence of a significant signal at $188.8 \mathrm{ppm}$ in the ${ }^{13} \mathrm{C}$ NMR spectrum (Figure S10). This signal could be attributed to a doubly conjugated carbonyl group, which might be bonded to a pyridinyl unit and to a carbon-carbon double bond, in conformity with the disconnection $b$.
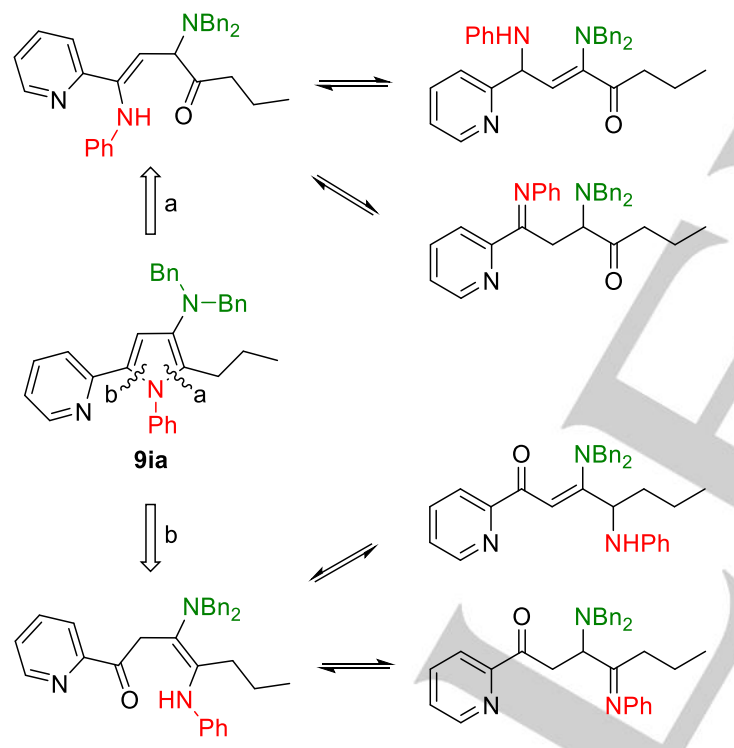

Scheme 14. Potential precursors of the pyrrole 9ia.

The reaction between indolizine $\mathbf{1} \mathbf{i}$ and nitrosobenzene (2a) was also analyzed by GC-MS and HRMS/Q-TOF after $10 \mathrm{~min}$ (Figures S11 and S12). The presence of a peak of $m / z 278$ was confirmed by both techniques; this peak diminished in intensity with the reaction course and disappeared after completion of the reaction, thus evidencing its role as a reaction intermediate. Several structures match the $\mathrm{m} / \mathrm{z} 278$ and some of the fragmentations observed (Figure $8, \quad \mathbf{A}$ and $\mathbf{B}$ ). This very important finding demonstrates that the nitroso compoundderived fragment is incorporated first and the dibenzylamino group second, prior to the ring closure. A broad peak at longer retention time was also observed by GC-MS; although the molecular ion was not brought into view, the average fragmentation points to structures that might be the immediate precursors of the pyrroles 9 (Figure 8, C-E).

The same labeling procedure as for the $\beta$-enaminones was applied in the synthesis of pyrroles in order to ascertain the origin of the oxygen atom in the postulated intermediate (Scheme 15). However, no incorporation of ${ }^{18} \mathrm{O}$ was observed in the corresponding GC-MS spectrum (Figure S13), again pointing to nitrosobenzene as the probable source of oxygen.

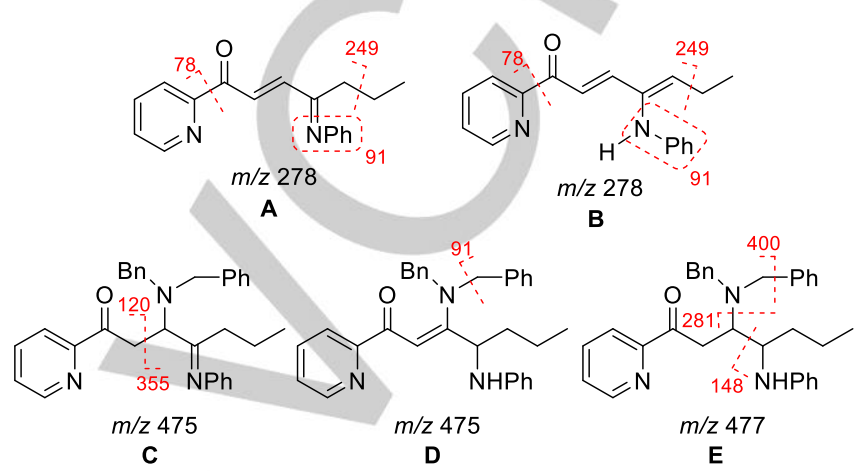

Figure 8. Structures and MS fragmentation proposed for some potential intermediates in the pyrrole synthesis.

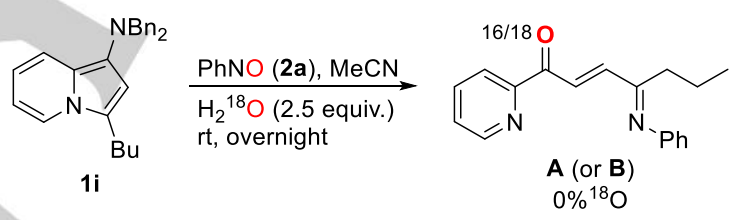

Scheme 15. Labeling experiment in the synthesis of the intermediate of pyrrole 9ia.

On the basis of the above results, a tentative reaction mechanism has been set forth considering that the source of oxygen is the nitroso compound (Scheme 16). The indolizine reacts through its 1 position with nitrosobenzene to form a $\mathrm{C}-\mathrm{N}$ and/or C-O bond, followed by intramolecular displacement of dibenzylamide ion. This ion (or less probably, the ethoxide ion) could deprotonate the pseudo-benzylic $\mathrm{H}$ of the resulting intermediate to give a 1,3-dienol structure. Intermolecular delivery of the anilino moiety $(\mathrm{PhNH})$, accompanied by deprotonation, would provide one of the pyrrole precursors in Figure $8(\mathbf{A})$. There is little chance that the rupture of the $\mathrm{N}-\mathrm{O}$ bond is promoted by nucleophilic attack of $\mathrm{Bn}_{2} \mathrm{~N}^{-}$or $\mathrm{EtO}^{-}$on the $\mathrm{N}$ atom, as this would entail (a) the participation of two equivalents of nitrosobenzene, (b) the formation of the respective hydrazine or hydroxylamine derivatives (not detected) and (c) the difficulty to explain the reaction in non-nucleophilic solvents or in the absence of solvent (Table 4). Michael addition of dibenzylamine to $\mathbf{A}$ would generate $\mathbf{C}$, the tautomer of which (D) could suffer intramolecular condensation and aromatization to the final pyrrole. The release of water from the suggested intramolecular condensation is in agreement with the reaction slowing down in a mixture of $\mathrm{EtOH} / \mathrm{H}_{2} \mathrm{O}$ (Figure 7). 


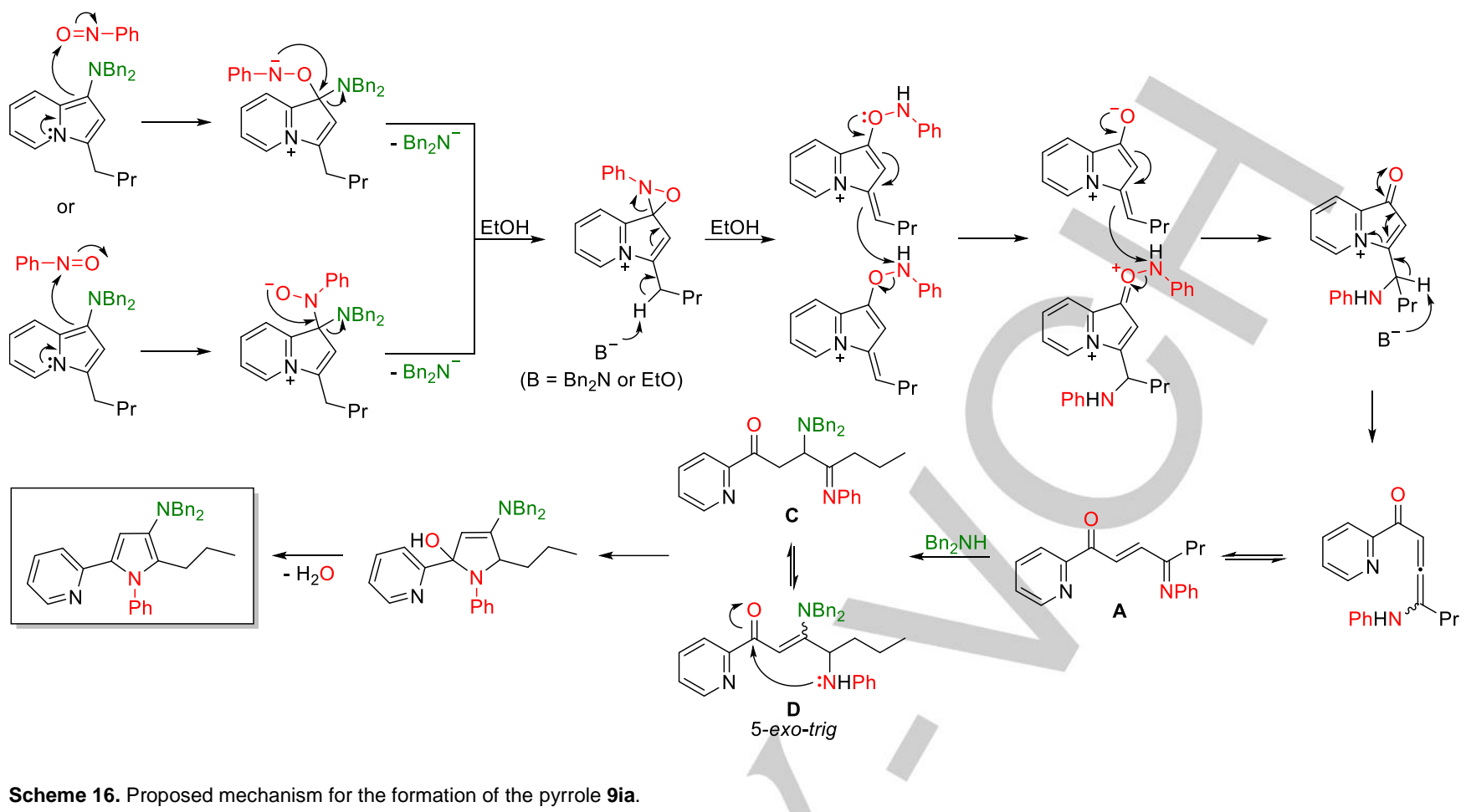

Although the accuracy of some of the steps of the reaction mechanism depicted in Scheme 16 is arguable, we believe that the reaction sequence established based on experimentation is reasonable, that is to say: (a) reaction of the indolizine with nitrosobenzene, (b) elimination of dibenzylamine, (c) cleavage of the N-O bond, (d) reincorporation of dibenzylamine, (d) intramolecular cyclization and (e) aromatization.

\section{Conclusion}

Concluding this study, we can say that 1-aminoindolizines are versatile compounds that, under substrate control, can be transformed into $\beta$-enaminones or tetrasubstituted pyrroles by reaction with nitrosoarenes; 3 -aryl-substituted indolizines give rise to $\beta$-enaminones ( $35-88 \%$ yield), whereas the 3 -alkylsubstituted counterparts give rise to pyrroles (33-96\% yield), all containing a pyridinyl fragment. Both reactions have some notable characteristics in common, namely: (a) they proceed in the absence of catalyst, (b) at room temperature, (c) in air, (d) they can be implemented in one pot from commercial chemicals, without the need to isolate the intermediate indolizine, and (e) the experimental is adaptable to gram-scale synthesis. Unconventional reaction pathways have been delineated to rationalize the formation of these products. Furthermore, the $\beta$ enaminones are produced stereoselectively with a regioselectivity unattainable by the previously reported experimental operations. There is no room for doubt about the usefulness of this type of compounds, as illustrated in the synthesis of various nitrogen heterocycles. Equally appealing is the structure of the pyrroles, which are $\mathrm{N}$-arylated and uncommonly functionalized with an amino group ${ }^{[25]}$ and a pyridinyl segment that might make them suitable as ligands in catalysis. This approach to $\mathrm{N}$-aryl pyrroles overcomes the hurdles encountered in the pyrrole $\mathrm{N}$-arylation when amino or heterocyclic substituents are present. ${ }^{[1 a]}$ Drug-discovery projects at the individual compound synthesis demand robust, scalable and safe methods; therefore, the fascinating heterocycle transmutation presented in this survey can be also incorporated in a synthetic toolkit that can pave the way for the discovery of new and more efficient drugs, given the significance in this field of pyridines, $\beta$-enaminones and pyrroles.

\section{Experimental Section}

\section{General}

Melting points were obtained with a Reichert Thermovar apparatus and are uncorrected. Infrared analysis was performed with a Jasco 4100LE (Pike MIRacle ATR) spectrophotometer; wavenumbers ( $\tilde{u})$ are given in $\mathrm{cm}^{-1}$. NMR spectra were recorded on Bruker Avance 300 and 400 spectrometers (300 and $400 \mathrm{MHz}$ for ${ }^{1} \mathrm{H}$ NMR; 75 and $101 \mathrm{MHz}$ for ${ }^{13} \mathrm{C}$ NMR); chemical shifts are given in $(\delta)$ parts per million and coupling constants $(J)$ in Hertz. Mass spectra (El) were obtained at $70 \mathrm{eV}$ on an Agilent 5763 GC-MS apparatus; fragment ions in $\mathrm{m} / \mathrm{z}$ with relative intensities (\%) in parentheses. HRMS analyses were also carried out in the electron impact mode (EI) at $70 \mathrm{eV}$ using an Agilent 7200 spectrometer with a quadrupole analyzer or with a LC-ESI-TOF system. Elemental analysis was performed on a Leco Micro TruSpec CHNS microanalyzer. The purity of volatile compounds and the chromatographic analyses (GLC) were determined with a Youling 6100 instrument equipped with a flame ionization detector and a $30 \mathrm{~m}$ capillary column (0.32 $\mathrm{mm}$ diameter, $0.25 \mu \mathrm{m}$ film thickness), using nitrogen (2 $\mathrm{mL} / \mathrm{min})$ as carrier gas, $T_{\text {injector }}=270^{\circ} \mathrm{C}, T_{\text {column }}=80^{\circ} \mathrm{C}(3 \mathrm{~min})$ and 80 $270{ }^{\circ} \mathrm{C}\left(20{ }^{\circ} \mathrm{C} / \mathrm{min}\right)$; retention times $\left(t_{\mathrm{R}}\right)$ are given in min. Analytical thinlayer chromatography (TLC) was carried out on TLC plastic sheets with 
silica gel $60 \mathrm{~F}_{254}$ (Merck). Column and preparative chromatography were performed using silica gel 60 of $40-60$ microns and P/UV254, respectively (hexane/EtOAc as eluent).

$\mathrm{Bn}_{2} \mathrm{ND}$ was prepared by mixing $\mathrm{Bn}_{2} \mathrm{NH}(1 \mathrm{mmol})$ with $\mathrm{D}_{2} \mathrm{O}(1 \mathrm{~mL})$ and stirring overnight at room temperature. After this time, the crude was extracted with $\mathrm{Et}_{2} \mathrm{O}$ and the solvent was evaporated. The deuterated amine was used without any further purification. The deuterated alkynes ( $\mathrm{PhC} \equiv \mathrm{CD}$ and $\mathrm{BuC} \equiv \mathrm{CD})$ were prepared by suspending CuNPs/C (0.5 mol\%) in $\mathrm{D}_{2} \mathrm{O}(1 \mathrm{~mL})$ followed by the addition of the terminal alkyne (1 $\mathrm{mmol}$ ); the resulting mixture was stirred at $70{ }^{\circ} \mathrm{C}$ overnight. Then, the product was filtered and extracted with $\mathrm{Et}_{2} \mathrm{O}$. The deuterated alkyne was used without any further purification.

\section{General procedure for the synthesis of the indolizines 1}

The indolizines 1 were prepared from pyridine-2-carbaldehydes, secondary amines and terminal alkynes using two methods: the aldehyde $(2 \mathrm{mmol})$, amine $(2 \mathrm{mmol})$ and alkyne $(2 \mathrm{mmol})$ were added to a reactor tube containing (a) CuNPs/C ( $80 \mathrm{mg}$, ca. $0.5 \mathrm{~mol} \%$ ) and dichloromethane $\left(2.0 \mathrm{~mL}\right.$ ) for the indolizines $\mathbf{1 a}-\mathbf{1} \mathbf{g},{ }^{[16]}$ or (b) Cul (38 mg, $\left.10 \mathrm{~mol} \%\right)$ under solvent-free conditions for the indolizines $\mathbf{1 i}-1 \mathbf{s}$. The reaction mixture was warmed to $70 \stackrel{\circ}{\circ}$ without the exclusion of air and monitored by TLC and/or GLC until total or steady conversion of the starting materials. The solvent was removed in vacuum; EtOAc $(2 \mathrm{~mL})$ was added to the resulting mixture followed by filtration through Celite and washing with additional EtOAc $(4 \mathrm{~mL})$. The reaction crude obtained after evaporation of the solvent was purified by column chromatography (silica gel, hexane/EtOAc) to give the corresponding indolizine 1 . Indolizine $1 \mathrm{~h}$ was synthesized following our reported procedure, ${ }^{[17 \mathrm{~b}]}$ by stirring the indolizine 1a $(1.94 \mathrm{~g}, 5 \mathrm{mmol})$ in HOAc $(5 \mathrm{~mL})$ at room temperature for $6 \mathrm{~h}$, followed by basification with saturated $\mathrm{NaHCO}_{3}$, extraction with EtOAc (3 $\times 20 \mathrm{~mL}$ ) and solvent evaporation. The reaction crude was purified by column chromatography (silica gel, hexane/EtOAc) to give the pure indolizine 1h. Deuterated indolizines 1a-[D] $(78 \% \mathrm{D})$ and 1i-[D] $(72 \% \mathrm{D})$ were prepared following the general procedure but starting from pyridine2-carbaldehyde, $\mathrm{Bn}_{2} \mathrm{ND}$, and $\mathrm{PhC} \equiv \mathrm{CD}$ and $\mathrm{BuC} \equiv \mathrm{CD}$, respectively, in $\mathrm{D}_{2} \mathrm{O}$.

\section{General procedure for the synthesis of the nitroso compounds 2}

The corresponding amine $(1 \mathrm{mmol})$ was dissolved in $\mathrm{CH}_{2} \mathrm{Cl}_{2}(2 \mathrm{~mL})$ and added to a solution of Oxone (1229 mg, 2 equiv.) in $\mathrm{H}_{2} \mathrm{O}(2 \mathrm{~mL})$ or to a solution of $m$-chloroperbenzoic acid (690 mg, 4 equiv.) in $\mathrm{CH}_{2} \mathrm{Cl}_{2}(2 \mathrm{~mL})$. After completion of the reaction, the crude was extracted with $\mathrm{CH}_{2} \mathrm{Cl}_{2}$ (3 $\times 10 \mathrm{~mL}$ ), dried with $\mathrm{MgSO}_{4}$ and evaporated under vacuum. The nitroso compounds were used without any further purification in the next step.

\section{General procedure for the synthesis of the $\beta$-enaminones 3}

The nitroso compound $2(0.3 \mathrm{mmol})$ was added to a solution of the indolizine $1(0.3 \mathrm{mmol})$ in $\mathrm{MeCN}(3 \mathrm{~mL})$ in a reactor tube. The mixture was stirred at ambient temperature overnight, followed by solvent evaporation under vacuum and purification by column chromatography (silica gel, hexane/EtOAc), to give the pure $\beta$-enaminones 3 .

\section{General procedure for the synthesis of the pyrroles 9}

The indolizine $1(0.3 \mathrm{mmol})$ was dissolved in $\mathrm{EtOH}(3 \mathrm{~mL})$ in a reactor tube, followed by the addition of $\operatorname{ArNO}(2,0.3 \mathrm{mmol})$ and stirring at ambient temperature overnight. The solvent was removed under vacuum and the reaction crude was purified by column chromatography (silica gel, hexane/EtOAc) to give the pure pyrroles 9 .
Selected X-ray crystallographic data for 3aa: $\mathrm{C}_{20} \mathrm{H}_{16} \mathrm{~N}_{2} \mathrm{O}, M=300.35$, monoclinic, space group $P$ 21/c, yellow plates, $a=11.5001(16), b=$ 11.1411(15), $c=12.4298(17) \AA ̊ ., T=295(1), Z=4, R=0.0386, \mathrm{GOF}=$ 1.010.

Selected X-ray crystallographic data for 9ia: $\mathrm{C}_{32} \mathrm{H}_{31} \mathrm{~N}_{3}, M=457.60$, monoclinic, space group C c, colorless plates, $a=16.960(3), b=$ 8.7394(13), $c=17.960$ (3) $\AA, T=295(1), Z=4, R=0.0451$, GOF $=1.023$.

\section{Acknowledgements}

This work was generously supported by the the Spanish Ministerio de Ciencia, Innovación y Universidades (MICIU; grant no. CTQ2017-88171-P), the Generalitat Valenciana (GV; grant no. AICO/2017/007), and the Instituto de Síntesis Orgánica (ISO). M.J.G.-S. is grateful to the ISO for a pre-doctoral grant (contract no. I-PAS-11/16).

Keywords: enaminones $\cdot$ indolizines $\cdot$ nitroso compounds • nitrogen heterocycles $\bullet$ pyrroles

[1] Perspectives: a) D. C. Blackemore, L. Castro, I. Churcher, D. C. Rees, A. W. Thomas, D. M. Wilson, A. Wood, Nat. Chem. 2018, 10, 383-394 b) J. Boström, D. G. Brown, R. J. Young, G. M. Keserü, Nat. Rev. Drug Discovery 2018, 17, 709-727; review: c) K. R. Campos, P. J. Coleman, J. C. Alvarez, S. D. Dreher, R. M. Garbaccio, N. K. Terrett, R. D. Tillyier, M. D. Truppo, E. R. Parmee, Science 2019, 363, eaat0805.

[2] a) Miniperspective: R. D. Taylor, M. MacCoss, A. D. G. Lawson, J. Med Chem. 2014, 57, 5845-5859; b) C. Allais, J.-M. Grassot, J. Rodriguez, T. Constantieux, Chem. Rev. 2014, 114, 10829-10868; c) P. Jeschke in Bioactive Heterocyclic Compound Classes: Agrochemicals (Eds.: C. Lamberth, J. Dinges), Wiley-VCH, Weinheim, 2012; Chapter 17.

[3] a) Review: S. S. Gholap, Eur. J. Med. Chem. 2016, 110, 13-31; b) X.-C. Huang, X. Xiao, Y.-K. Zhang, T. T. Talele, A. A. Salim, Z.-S. Chen, R. J. Capon, Mar. Drugs 2014, 12, 3818-3837; c) Review: M. Baumann, I. R Baxendale, S. V. Ley, N. Nikbin, Beilstein J. Org. Chem. 2011, 7, 442495; d) C. Lamberth in Bioactive Heterocyclic Compound Classes: Agrochemicals (Eds.: C. Lamberth, J. Dinges), Wiley-VCH, Weinheim, 2012, Chapter 13; e) P. Baiocco, G. Poce, S. Alfonso, M. Cocozza, G. C. Porretta, G. Colotti, M. Biava, F. Moraca, M. Botta, V. Yardley, A Fiorillo, A. Lantella, F. Malatesta, A. Ilari, ChemMedChem 2013, 8 1175-1183; f) D. Murugesan, A. Mital, M. Kaiser, D. Shackleford, J. Morizzi, K. Katneni, M. Campbell, A. Hudson, S. A. Charman, C. Yeates, I. H. Gilbert, J. Med. Chem. 2013, 56, 2975-2990.

[4] Reviews: a) U. Kuckländer in The Chemistry of Enamines, Part 1 (Ed. Z. Rappoport), Wiley, Chichester, 1994, Chapter 10; b) A.-Z. A. Elassar, A. A. El-Kahir, Tetrahedron 2003, 59, 8463-8480; c) G. Negri, C. Kascheres, A. J. Kascheres, J. Heterocycl. Chem. 2004, 41, 461-491; d) B. Stanovnik, J. Svete, Chem. Rev. 2004, 104, 2433-2480; e) A. K. Chattopadhyay, S. Hanessian, Chem. Commun. 2015, 51, 1643716449; f) A. K. Chattopadhyay, S. Hanessian, Chem. Commun. 2015, $51,16450-16467$

[5] a) H. Kubo, J. Kobayashi, K. Higashiyama, J. Kamei, Y. Fujii, S Ohmiya, Biol. Pharm. Bull. 2000, 23, 1114-1117; b) K. R. Scott, G. O Rankin, J. P. Stables, M. S. Alexander, I. O. Edafiogho, V. A. Farrar, K. R. Kolen, J. A. Moore, L. D. Sims, A. D. Tonnut, J. Med. Chem. 1996, 38, 4033-4043; c) A. Kaushik, A.; Ogbaghebriel, Sharma, A. AAA's Quinolones \& Fluoroquinolones: Man-made Antibiotics, LAP Lambert, Düsseldorf, 2011.

[6] See, for instance: a) Q. Zhang, X. Liu, X. Xin, R. Zhang, Y. Liang, D. Dong, Chem. Commun. 2014, 50, 15378-15380, b) R. Yan, X. Li, X. Yang, X. Kang, L. Xiang, G. Huang, Chem. Commun. 2015, 51, 2573- 
2576; c) J.-P. Wan, S. Cao, Y. Liu, Org. Lett. 2016, 18, 6034-6037; d) F. Wang, L. Jin, L. Kong, X. Li, Org. Lett. 2017, 19, 1812-1815.

[7] a) K. D. Bhatte, P. J. Tambade, K. P. Dhake, B. M. Bhanage, Catal. Commun. 2010, 11, 1233-1237; b) H. Seki, G. I. Georg, J. Am. Chem. Soc. 2010, 132, 15512-15513; c) T. Miura, Y. Funakoshi, M. Morimoto, T. Biyajima, M. Murakami, J. Am. Chem. Soc. 2012, 134, 1744017443; d) L. Shi, L. Xue, R. Lang, C. Xia, F. Li, ChemCatChem 2014, 6 2560-2566; e) K. Xu, Z. Zhang, P. Qian, Z. Zha, Z. Wang, Chem. Commun. 2015, 51, 11108-11111.

[8] Reviews: a) A. V. Gulevich, A. S. Dudnik, N. Chernyak, V. Gevorgyan, V. Chem. Rev. 2013, 113, 3084-3213; b) N. Yoshikai, Y. Wei, Asian J. Org. Chem. 2013, 2, 466-478; c) V. Estévez, M. Villacampa, J. C. Menéndez, Chem. Soc. Rev. 2014, 43, 4633-4657; d) S. Vessally, RSC Adv. 2016, 6, 18619-18631; e) S. Anuradha, P. Piplani, J. Heterocycl. Chem. 2017, 54, 27-35; f) T. Fujita, J. Ichikawa, Heterocycles 2017, 95, 694-714.

[9] Selected examples: a) O. A. Attanasi, G. Favi, F. Mantellini, G. Moscatelli, S. Santeusanio, J. Org. Chem. 2011, 76, 2860-2866; b) M. Zhang, X. Fang, H. Neumann, M. Beller, J. Am. Chem. Soc. 2013, 135, 11384-11388; c) P. Liu, J. Liu, H. Wang, Y. Pan, H. Liang, Z.-F. Chen, Chem. Commun. 2014, 50, 4795-4798; d) Y. Zheng, Y. Wang, Z. Zhou, Chem. Commun. 2015, 51, 16652-16655; e) G. M. Torres, J. S Quesnel, D. Bijou, B. A. Arndtsen, J. Am. Chem. Soc. 2016, 138, 73157324.

[10] a) Y. Jiang, W. C. Chan, C.-M. Park, J. Am. Chem. Soc. 2012, 134, 4104-4107; b) W. Du, M.-N. Zhao, Z.-H. Ren, Y.-Y. Wang, Z.-H. Guan, Chem. Commun. 2014, 50, 7437-7439; c) D. K. Tiwari, J. Pogula, B Sridhar, D. K. Tiwari, P. R. Likhar, Chem. Commun. 2015, 51, 1364613649.

[11] a) S. Rakshit, F. W Patureau, F. Glorius, J. Am. Chem. Soc. 2010, 132, 9585-9587; b) D. R. Stuart, P. Alsabeh, M. Kuhn, K. Fagnou, K. J. Am Chem. Soc. 2010, 132, 18326-18339; c) J. Zheng, L. Huang, Z. Li, W. Wu, J. Li, H. Jiang, Chem. Commun. 2015, 51, 5894-5897; d) S. Undeela, S. Thadkapally, J. B. Nanubolu, K. K. Singarapu, R. S. Menon, Chem. Commun. 2015, 51, 13748-13751; e) K. Matsui, M. Shibuya, Y Yamamoto, Commun. Chem. 2018, 1, 21.

[12] a) W. Geng, W.-X. Zhang, W. Hao, Z. Xi, J. Am. Chem. Soc. 2012, 134, 20230-20233; b) W. W. Tan, N. Yoshikai, Chem. Sci. 2015, 6, 64486455 ; c) X. Chen, Y. Xie, X. Xiao, G. Li, Y. Deng, H. Jiang, W. Zeng, Chem Commun. 2015, 51, 15328-15331; d) S. M. A. H. Siddiki, A. S. Touchy, C. Caudhari, K. Kon, T. Toyao, K. Shimizu, Org. Chem. Front. 2016, 3, 846-851.

[13] a) D. J. St. Cyr, B. A. Arndtsen, J. Am. Chem. Soc. 2007, 129, 1236612367; b) J.-Y. Liao, P.-L. Shao, Y. Zhao, J. Am. Chem. Soc. 2015, 137, $628-631$.

[14] a) A. R. Kelly, M. H. Kerrigan, P. J. Walsh, J. Am. Chem. Soc. 2008, 130, 4097-4104; b) B. T. Parr, S. A. Green, H. M. L. Davies, J. Am Chem. Soc. 2013, 135, 4716-4718; c) A.-H. Zhou, Q. He, C. Shu, Y.-F. Yu, S. Liu, T. Zhao, W. Zhang, X. Lu, L.-W. Ye, Chem. Sci. 2015, 6, 1265-1271.

[15] See, for instance: a) P. Abdulkin, Y. Moglie, B. R. Knappett, D. A. Jefferson, M. Yus, F. Alonso, A. E. H. Wheatley, Nanoscale 2013, 5, 342-350; b) For a recent application, see: I. Martín-García, F. Alonso, Chem. Eur. J. 2018, 24, 18857-18862.

[16] M. J. Albaladejo, F. Alonso, M. J. González-Soria, ACS Catal. 2015, 5, 3446-3456.

[17] a) M. J. Albaladejo, M. J. González-Soria, F. Alonso, J. Org. Chem. 2016, 81, 9707-9717; b) M. J. González-Soria, F. Alonso, Green Chem. 2018, 20, 701-712.

[18] CCDC-1588062 (3aa) and CCDC-1588064 (9ia) contain the supplementary crystallographic data for this paper. These data can be obtained free of charge from The Cambridge Crystallographic Data Centre via www.ccdc.cam.ac.uk/data_request/cif

[19] a) J. Chen, X. Yang, M. Liu, H. Wu, J. Ding, W. Su, Synth. Commun. 2009, 39, 4180-4198; b) H. A. Stefani, I. M. Costa, D. de O. Silva Synthesis 2000, 1526-1528; c) A. R. Khosropour, M. M. Khodaei, M.
Kookhazadeh, Tetrahedron Lett. 2004, 45, 1725-1728; d) C. J. Valduga, A. Squizani, H. S. Braibante, M. E. F. Braibante, Synthesis 1998, 10191022.

[20] M. Gaber, S. A. El-Daly, Y. S. Y. El-Sayed, J. Mol. Struct. 2009, 922, 51-57.

[21] D. Prat, A. Wells, J. Hayler, H. Sneddon, R. McElroy, S. AbouShehadad, P. J. Dunne, Green Chem. 2016, 18, 288-296.

[22] L. Zhang, S.-H. Xiang, J. (Joelle) Wang, J. Xiao, J. Q. Wang, B. Tan, Nat. Commun. 2019, 10:566

[23] C. R. De Souza, A. C. Gonçalves, M. F. Z. J Amaral, A. A. Dos Santos, G. C. Clososki, Targets Heterocycl. Syst. 2016, 20, 365-392.

[24] G. Wang, G. Piva de Silva, N. E. Wiebe, G. M. Fehr, R. L. Lewis, RSC Adv. 2017, 7, 48848-48852.

[25] Selective removal of one or both $N$-benzyl groups in pyrroles 9 is expected to be feasible following our reported procedures. ${ }^{[17 a]}$ 
Entry for the Table of Contents (Please choose one layout)

\section{RESEARCH ARTICLE}

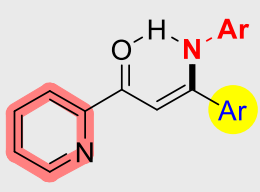

$\frac{\text { ArNO }}{\mathrm{R}^{3}=\mathrm{Ar}}$
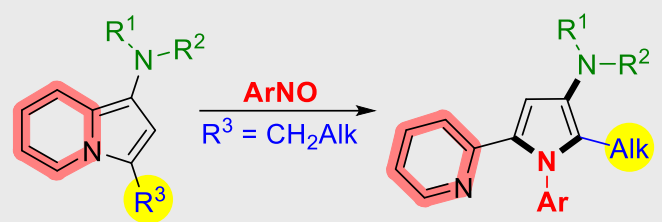

As good as it gets: Pyridine-containing $\beta$-enaminones and $N$-aryl pyrroles have been prepared from indolizines and nitroso compounds in the absence of catalyst, at room temperature, in air, in one-pot from commercial materials and in gram scale.
María José González-Soria, Francisco Alonso*

\section{Page No. - Page No.}

Substrate-controlled divergent synthesis of enaminones and pyrroles from indolizines and nitroso compounds 